\title{
Characterization of a hydroxyproline-rich glycoprotein in pearl millet and its differential expression in response to the downy mildew pathogen Sclerospora graminicola
}

\author{
Neerakkal Sujeeth • Ramachandra K. Kini - Sekhar Shailasree • \\ Eelco Wallaart • Shekar H. Shetty $\cdot$ Jacques Hille
}

Received: 23 March 2011/Revised: 6 October 2011/Accepted: 18 October 2011/Published online: 12 November 2011

(C) The Author(s) 2011. This article is published with open access at Springerlink.com

\begin{abstract}
A monoclonal antibody, JIM 20, derived against an extensin type of hydroxyproline-rich glycoprotein (HRGP) from pea, showed high affinity for HRGP in pearl millet [Pennisetum glaucum (L.) R. Br.]. Electrophoretic separation of Tris-SDS extracted proteins from suspension cells of pearl millet revealed a range of PMHRGP polypeptides having a glycan epitope, which reacted with JIM 20. A high molecular mass band, probably an HRGP aggregate or polymer, and a few low molecular mass polypeptides were recognized by JIM 20 during Western blot analysis. Treatment of pearl millet suspension cells with hydrogen peroxide in the presence of an endogenous peroxidase resulted in insolubilization of HRGP polypeptides with molecular weights between 45 and $33 \mathrm{kDa}$. To investigate the gene coding for an extensin type of HRGP, a fosmid-based genomic library of pearl millet having a fourfold genome coverage was constructed. A partial sequence of $378 \mathrm{bp}$ of an HRGP gene was obtained by PCR amplification of pearl millet DNA with a primer pair designed from the conserved regions of
\end{abstract}

Communicated by B. Barna.

N. Sujeeth $(\bowtie) \cdot$ J. Hille

Molecular Biology of Plants, Groningen Biomolecular Sciences

and Biotechnology Institute, Centre for Life Sciences,

University of Groningen, Nijenborgh 7,

9747 AG Groningen, The Netherlands

e-mail: s.neerakkal@rug.nl

N. Sujeeth $\cdot$ R. K. Kini $\cdot$ S. Shailasree $\cdot$ S. H. Shetty

Department of Studies in Biotechnology, Manasagangotri,

University of Mysore, Mysore 570006, Karnataka, India

E. Wallaart

Sylphium Life Sciences, Duurswoldlaan 22,

9727 DJ Groningen, The Netherlands monocotyledon extensin type of HRGPs. Screening the genomic library using the homologous probe developed from the 378-bp PCR product resulted in the isolation of five fosmid clones. Restriction mapping of these fosmids resulted in an 11.8-kb region around an HRGP gene in pearl millet. The newly characterized gene, $P M-H R G P$, had all the characteristic features of a monocotyledon extensin type of HRGP. An intron at the $3^{\prime}$ untranslated region of the gene was identified by cDNA cloning. Differential expression of the PM-HRGP gene was observed during compatible and incompatible interactions of pearl millet with the downy mildew pathogen Sclerospora graminicola (Sacc) Schroet. Induced expression of the gene was observed only in case of an incompatible interaction.

Keywords Extensins - PM-HRGP - Fosmid pearl millet library $\cdot$ Downy mildew $\cdot$ Sclerospora graminicola

\section{Abbreviations \\ HRGP Hydroxyproline-rich glycoprotein \\ PRP Proline-rich proteins \\ SDS-PAGE Sodium dodecyl sulfate-polyacrylamide gel electrophoresis \\ qRT-PCR Quantitative real-time PCR}

\section{Introduction}

The mature plant cell wall contains proteins forming a positively charged network or frame to which negatively charged carbohydrates are attached (Cannon et al. 2008). Among the glycoprotein components of the plant cell wall, hydroxyproline-rich glycoproteins (HRGPs) are one of the important structural components with a wide range of roles 
including defense against plant pathogens. This superfamily of glycoproteins includes extensins, proline-rich proteins (PRPs) and arabinogalactan proteins (AGPs) (SommerKnudsen et al. 1998; Jose-Estanyol and Puigdomenech 2000; Showalter et al. 2010). The extensins and PRPs are known to be insoluble proteins, whereas AGPs are soluble proteins.

The dicotyledonous extensins constitute a large family of glycoproteins that function in diverse aspects of plant growth, development and in some cases in plant defense (Showalter 1993). Accumulation and cross-linking of extensins provide protective functions during pathogen attack and wounding in many plants (Templeton et al. 1990; Bowles 1990; Jackson et al. 2001). The expression of extensin transcripts can be induced by various treatments, such as wounding, pathogen infection and mechanical signals (Merkouropoulos et al. 1999; Yoshiba et al. 2001). However, oxidative cross-linking of these cell wall proteins is elicited very rapidly upon pathogen infection, before deployment of transcription-dependent defenses (Brisson et al. 1994; El-Gendy et al. 2001).

Extensin genes are well characterized in dicots, and the existence of a multigene family for extensin has been described in carrot (Chen and Varner 1985) and oil seed rape (Evans et al. 1990). The Arabidopsis genome encodes 20 closely homologous extensin polypeptides with distinct patterns of expression at the organ/tissue level (Zimmermann et al. 2004). The search for extensin in monocots resulted in the characterization of a much simpler system, probably encoded by a single gene as in the case of maize, sorghum and rice. The first monocot $H R G P$ gene with a single Ser-(Hyp $)_{4}$ motif near the $\mathrm{C}$ terminus, a variant of the Ser-(Hyp) $)_{4}$-rich extensin family in dicots, was identified in maize (Stiefel et al. 1988, 1990). Similar structures were reported in sorghum (Raz et al. 1991) and also in rice with the exception that the C-terminus Ser-Hyp ${ }_{4}$ motif is absent (Caelles et al. 1992). All these monocot variants of extensin were classified as a separate group called proline/hydroxyproline-rich glycoproteins (P/HRGPs) along with other PRPs by Sommer-Knudsen et al. (1998). They also indicated that P/HRGPs may have been evolved from extensin by deletion of $\mathrm{Ser}(\mathrm{Pro})_{4}$ repeats. JoseEstanyol and Puigdomenech (2000) reviewed and classified them under the extensin class based on the presence of a single Ser (Pro $)_{4}$ motif and having similar functional properties compared to other extensins characterized.

The cereal pearl millet [Pennisetum glaucum (L.) R. Br.] is a staple food grain of people living in the semi-arid tropics including parts of India and Africa. It is the seventh most important cereal crop worldwide, grown on about 15 million ha in Africa and around 12 million ha in Asia (Léder 2004). Due to its adaptation to drought and heat, pearl millet is an important crop that helps to attain food security where other cereals fail. The major constraint for its production is the downy mildew disease caused by the obligate, biotrophic, oomycetous pathogen Sclerospora graminicola (Sacc.) Schroet. It causes systemic infection in pearl millet that manifests itself as foliar symptoms and malformation of the panicles, resulting in severe grain loss. Even though several resistant cultivars have been developed by classical breeding programs, the resistance breaks down over a period of time due to the continuous evolution of the pathogen. A better understanding of the basis of resistance in pearl millet to the pathogen is essential for developing durable resistance strategies.

Previously, we showed that cell wall HRGPs in pearl millet accumulate in response to pathogen infection and elicitor treatments (Shailasree et al. 2004; Sujeeth et al. 2010). Here, we report the presence of an extensin type of PM-HRGP in pearl millet. A putative role of the protein in plant defense, as suggested by cross-linking observed in vitro, is discussed. Furthermore, a gene encoding the extensin type of $P M-H R G P$ in pearl millet was characterized. The accumulation of transcripts of this gene during interaction of pearl millet with $S$. graminicola, the downy mildew disease pathogen, has been studied.

\section{Materials and methods}

Analysis of hydroxyproline-rich glycoproteins

\section{Pearl millet suspension cell culture}

The pearl millet cell culture was raised from IP18296, a highly resistant cultivar by following the method of Vasil and Vasil (1981). The well-established suspension cells were regularly sub-cultured onto fresh medium at 1:5 dilution rates, at 10-day intervals and after ten sub-cultures the cells were used for the study. A cell culture $\left(10^{8}\right.$ cells $\left.\mathrm{ml}^{-1}\right)$ at the midpoint of the $\log$ phase of growth (16-day-old) was used for the experiments.

\section{Protein isolation and deglycosylation}

Total protein was extracted from the suspension cells by resuspending in $1 \mathrm{ml}$ of $100 \mathrm{mM}$ Tris- $\mathrm{HCl}$ (pH 7.4) containing $4 \%$ SDS in a handheld homogenizer. The homogenates were centrifuged for $5 \mathrm{~min}$ at $10,000 \times g$ and the supernatant was collected. A part of the extracted total protein was dialyzed against deionized $\mathrm{H}_{2} \mathrm{O}$, lyophilized and deglycosylated using HF in pyridine (Aldrich) following Vanholst and Varner (1984).

\section{Electrophoresis and Western blot analysis}

The supernatants collected from the crude and deglycosylated samples were assayed for protein (Lowry et al. 1951) 
and $60 \mu \mathrm{g}$ of protein was subjected to $12 \%$ SDS-PAGE. The separated proteins were stained with Coomassie blue. Glycoproteins in the gels were identified by Periodic acid Schiff (PAS) stain (Shailasree et al. 2004). For Western blot analysis, the separated proteins on SDS-PAGE were immediately blotted onto polyvinylidene difluoride (PVDF) membranes using the Multiphor II (Pharmacia, Freiburg, Germany) electrophoretic transfer apparatus according to the manufacturer's protocol. The blots were blocked in $2 \%$ fat-free milk in Tris-buffered saline (TBS: $10 \mathrm{mM}$ Tris- $\mathrm{HCl}$, pH 8.0 containing $150 \mathrm{mM} \mathrm{NaCl})$. All blots developed were probed separately with the monoclonal antibodies JIM20 and JIM12, specific to dicot extensins, and LM1, specific toward P/HRGPs from maize (Plant Probes, http://www.plantprobes.net/).

\section{Cross-linking analysis}

Aliquots of 1-ml cell culture were placed in microfuge tubes. Peroxidase-mediated cross-linking analysis was carried out by addition of $0.03 \% \quad \mathrm{H}_{2} \mathrm{O}_{2}$ and $0.03 \%$ $\mathrm{H}_{2} \mathrm{O}_{2}+0.05 \%$ sodium azide in two aliquots for $10 \mathrm{~min}$. Untreated cells were kept as a control. The cells were separated from the medium by centrifugation at $5,000 \times g$ for $5 \mathrm{~min}$ at room temperature and used for protein extraction and Western blot analysis using JIM 20.

PCR amplification of a conserved region of the HRGP gene

Pearl millet var.7042S, an inbred line (Thakur et al. 2001), was used as the standard pearl millet genotype. Genomic DNA isolation from pearl millet seedlings was carried out according to the protocol of Fulton et al. (1995). For PCR amplification of the $H R G P$ gene, primers were designed from the conserved regions of $H R G P$ gene sequences of maize (AJ131535), sorghum (X56010) and rice (X61280).
The primer sequences were PrRuG 2796 and PrRuG 2797 (Table 1). PCR of pearl millet genomic DNA was carried out using a high GC-rich PCR system (Roche, Mannheim, Germany). The GC-rich solution at a concentration of $0.5 \mathrm{M}$ was used for specific amplification of the gene product. The amplification was carried out by the PCR program: initial denaturation for $5 \mathrm{~min}$ at $95^{\circ} \mathrm{C}$ followed by 30 cycles of $30 \mathrm{~s}$ at $95^{\circ} \mathrm{C}, 1 \mathrm{~min}$ at $65^{\circ} \mathrm{C}, 1 \mathrm{~min}$ at $72^{\circ} \mathrm{C}$, and a final extension step of $7 \mathrm{~min}$ at $72^{\circ} \mathrm{C}$. To the blunt end PCR product obtained, a T overhang was added using Taq DNA polymerase (Fermentas). It was further cloned in the pGEM-T Easy vector (Promega, Madison, USA) and sequenced. This clone was used as an HRGP homologous probe for further studies.

Fosmid library construction

High molecular weight DNA (HMW DNA) was isolated from roots of 3-day-old pearl millet seedlings using the $G$ NOME DNA kit (MP Biomedicals, Illkirch, France) according to the manufacturer's protocol. To bring $80 \%$ of HMW DNA to $40-\mathrm{kb}$ size, it was subjected to random physical shearing by several passages through a sterile tip of a micropipette. It was further run on a $1 \%$ agarose gel in a CHEF-DR II pulsed field electrophoresis system (BIORAD) under the following conditions: 16 -h run time, $14^{\circ} \mathrm{C}$, $1-80 \mathrm{~s}$ pulses, $120^{\circ}$ angle in $0.5 \times \mathrm{TAE}$ at $6 \mathrm{~V} / \mathrm{cm}$. The gel eluted 40-kb DNA was end-repaired to blunt end and cloned into the pCC1FOS fosmid vector using the Copycontrol Fosmid Library Production kit (Epicentre Biotechnologies, Madison, USA), according to the manufacturer's instructions. The ligation mixture was then packed into phage particles using MaxPlax lambda packaging extracts (Epicentre Biotechnologies, Madison, USA). The packaged fosmid clones were titrated by serial dilutions in phage dilution buffer (PDB) and infected to $100 \mu \mathrm{l}$ of Phage T1-resistant E. coli (EP1300 ${ }^{\mathrm{TM}}$ plating strain) cells

Table 1 PCR primers used in this work

\begin{tabular}{lll}
\hline Primer & Description & Sequence $\left(5^{\prime}-3^{\prime}\right)$ \\
\hline PrRuG 2796 & Forward for 378-bp PCR product from pearl millet DNA & TCCAGGCCGACGCCGGCTACGGCTAC \\
PrRuG 2797 & Reverse for 378-bp PCR product from pearl millet DNA & TACGTCGGCGGAGTCGGCTTGG \\
PrRuG 2801 & Forward for $P M-H R G P$ intron search & GAGGATGGGCGCCGGCAAG \\
PrRuG 2812 & Reverse for $P M-H R G P$ intron search & CTTGGCCGGCTGGCTAGCACAC \\
PrRuG 2817 & Forward for $G A P D H$ gene characterization in pearl millet & ATGGGCAAGATTAAGATCGGAATCAACG \\
PrRuG 2818 & Reverse for $G A P D H$ gene characterization in pearl millet & CATGTGGCGGATCAGGTCGAC \\
PrRuG 2892 & Forward for $G A P D H$ gene qRT-PCR & CCAAGGCTGTCGGTAAGGTTC \\
PrRuG 2893 & Reverse for $G A P D H$ gene qRT-PCR & TGCTCGTTCAGAGCGATTCC \\
PrRuG 3293 & Forward for $P M-H R G P$ gene qRT-PCR & GCCTAAGCCGAAGCCACCAA \\
PrRuG 3294 & Reverse for $P M-H R G P$ gene qRT-PCR & GCGTGTAGGTCGGAGGAGTT \\
\hline
\end{tabular}


for $20 \mathrm{~min}$ at $37^{\circ} \mathrm{C}$. The phage-infected $E$. coli cells were plated onto LB agar plates containing chloramphenicol (12.5 $\mu \mathrm{g} / \mathrm{ml})$.

Pearl millet has a haploid genome size of $2,352 \mathrm{Mb}$ (Bennett et al. 2000). The required number of fosmid clones for a complete library of pearl millet was calculated as $N$ using the formula, $N=1 \mathrm{n}(1-P) / 1 \mathrm{n}(1-f)$ (Sambrook et al. 1989). A total of at least $2.7 \times 10^{5}$ clones were developed to get a complete library of pearl millet with a fourfold coverage of its haploid genome. For storage of the pearl millet library, $2.7 \times 10^{5}$ clones from the library plates were suspended in LB broth, pooled, aliquoted into $1 \mathrm{ml}$ sterile vials containing $20 \%$ glycerol and stored at $-80^{\circ} \mathrm{C}$.

Screening of the pearl millet DNA library

One aliquot of the pearl millet DNA library from $-80^{\circ} \mathrm{C}$ stocks was serially diluted to obtain about 20,000 colonies/ LB agar plate $(14-\mathrm{cm}$ diameter $\times 2.3-\mathrm{cm}$ thickness $)$ containing chloramphenicol. A total number of 18 of such plates were developed to obtain the complete library of pearl millet with fivefold genome equivalence (3.6 × $10^{5}$ clones). A colony blot hybridization (Sambrook et al. 1989) with the homologous HRGP probe labeled with $\left[{ }^{32} \mathrm{P}\right]-\mathrm{dCTP}$ was carried out. Positive clones isolated for the HRGP gene were sub-cultured overnight in LB broth and stored.

\section{Restriction analysis}

The fosmids were isolated from positive clones by the alkaline lysis method of Sambrook et al. (1989). The presence of a $40-\mathrm{kb}$ pearl millet DNA insert in the isolated fosmids was confirmed by Not I digestion followed by electrophoresis on the CHEF-DR II pulsed field electrophoresis system with the same conditions as mentioned in the library preparation protocol. Positive fosmids were digested with restriction enzymes, Ava I, Bam HI, Hind III and $H p a \mathrm{I}$, in single and double combinations, separated on an $0.8 \%$ agarose gel and transferred by Southern blotting to Hybond $\mathrm{N}^{+}$nylon membrane (Amersham, UK) following the protocol of Sambrook et al. (1989). The labeling and analysis of blots was carried out using the homologous HRGP probe labeled with $\left[{ }^{32} \mathrm{P}\right]-\mathrm{dCTP}$.

\section{HRGP sequence annotation}

A $3.5-\mathrm{kb}$ Bam HI fragment containing the HRGP fulllength gene sequence identified from restriction analysis was ligated into a dephosphorylated pUC18/19 vector linearized at the Bam HI site. The ligated product was cloned into the MM294 competent E. coli strain (Sylphium Life Sciences, Groningen, The Netherlands) and sequenced.
The sequence of the $3.5-\mathrm{kb}$ Bam HI fragment with the $H R G P$ full-length gene was deposited in the database [GenBank: GQ223398].

Cloning of the HRGP gene from cDNA of pearl millet

For cDNA synthesis, total RNA was extracted from seedlings of pearl millet using Spectrum Plant Total RNA kit (Sigma, St. Louis, USA). The DNA-free RNA was converted to cDNA by reverse transcription using the oligo- $5^{\prime}$ GCAGCGATC(T) ${ }_{28} \mathrm{~V}(\mathrm{~A} / \mathrm{C} / \mathrm{G}) \mathrm{N}(\mathrm{A} / \mathrm{C} / \mathrm{G} / \mathrm{T})-3^{\prime}$. The forward primer spanning the start codon of the PM-HRGP gene PrRuG 2801 and a reverse primer at a region 181-bp downstream from the stop codon, PrRuG 2812 (Table 1), was used for amplification of the HRGP gene area simultaneously from cDNA and genomic DNA of pearl millet. The resulting products from both reactions were further ligated into the pGEM-T easy vector, cloned and sequenced.

\section{Differential gene expression study}

For the analysis, an endogenous control gene glyceraldehyde-3-phosphate dehydrogenase (GAPDH) was newly isolated and characterized from pearl millet [GenBank: GQ398107]. The primer pair used for amplification was forward primer-PrRuG 2817 and reverse primer-PrRuG 2818 (Table 1).

\section{Plant material}

Pearl millet cultivars $7042 \mathrm{~S}$ (highly susceptible, HS) with $>25 \%$ downy mildew disease incidence (DMDI) and IP18296 (highly resistant, HR) with 0\% DMDI after inoculation with $S$. graminicola under field conditions were used. Two-day-old seedlings were root dip inoculated with zoospores of S. graminicola (Singh and Gopinath 1985). Seedlings dipped in sterile distilled water served as uninoculated control. The seedlings were harvested at different time intervals for total RNA isolations using Spectrum Plant Total RNA kit (Sigma, St. Louis, USA).

\section{Quantification of HRGP expression}

Reverse transcription of $1 \mu \mathrm{g}$ of DNA-free total RNA was performed using oligo (dT) primers for analysis. The relative expression of $P M-H R G P$ in relation to the endogenous control gene GAPDH was assessed by quantitative real-time PCR (qRT-PCR) using a 7500 Fast Real-Time PCR system (Applied Biosystems). The primers for qRTPCR were designed from the coding regions of $P M-H R G P$ (PrRuG 3293 and PrRuG 3294) and the GAPDH gene (PrRuG 2892 and PrRuG 2893) (Table 1). Twenty-microliter PCR reactions contained diluted cDNA, $2 \times$ Power 
SYBR Green Master mix (Applied Biosystems, Foster City, CA) and $250 \mathrm{nM}$ of forward and reverse primers (both for HRGP and GAPDH). Thermal cycling conditions were $95^{\circ} \mathrm{C}$ for $10 \mathrm{~min}$ followed by 40 cycles of $95^{\circ} \mathrm{C}$ for $15 \mathrm{~s}$ and $60^{\circ} \mathrm{C}$ for $1 \mathrm{~min}$. Following amplification, a dissociation stage was performed to check for nonspecific PCR products. Specificity of the amplicons was checked on an agarose gel of $1.2 \%$. Induction of genes (fold increase) at different time points of inoculation was compared with RNAs from the 0-h sample and calculated using the comparative threshold $\left(2^{-\Delta \Delta C_{\mathrm{T}}}\right)$ method of Livak and Schmittgen (2001). The PM-HRGP gene expression was normalized to that of the control GAPDH gene during quantitative measurement.

\section{Results}

Monoclonal antibody JIM20 binds to PM-HRGP in pearl millet

Coomassie blue staining of SDS-PAGE separated total proteins from suspension cells of pearl millet showed several bands ranging from lower to higher molecular mass (Lane 1, Fig. 1). The deglycosylated sample showed two proteins with molecular weights 37 and $30 \mathrm{kDa}$ (Lane 2, Fig. 1). The PAS staining for glycoproteins staining revealed the presence of a high molecular mass range fuzzy band, a glycan-rich aggregate or polymer in the total protein extract (Lane 3, Fig. 1), which disappeared upon deglycosylation of the sample (Lane 4, Fig. 1). The high
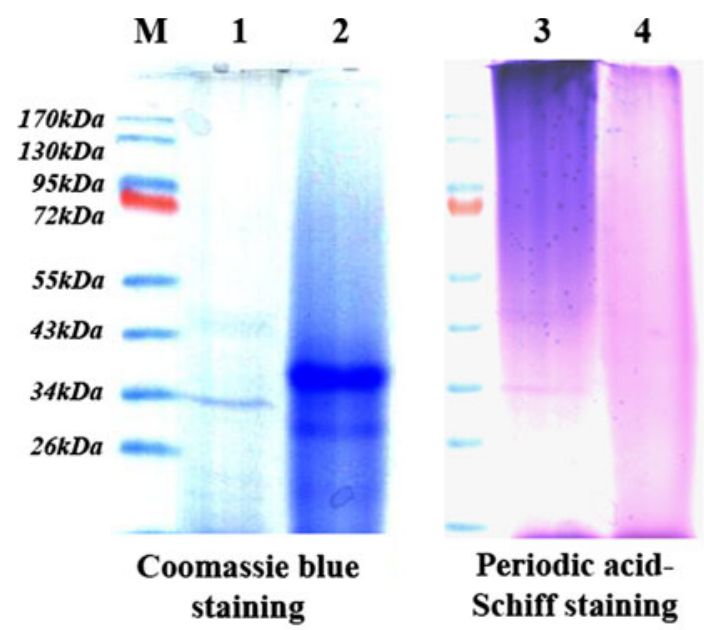

Fig. 1 Analysis of Tris- $\mathrm{HCl}$ and SDS extracted proteins from pearl millet suspension cells. Lanes 1 and 2 Coomassie blue staining of crude and deglycosylated protein samples, respectively; lanes 3 and 4 periodic acid Schiff staining of crude and deglycosylated protein samples, respectively; lanes 5 and 6 Western blot analysis using JIM 20 monoclonal antibody on crude and deglycosylated protein molecular mass band observed during the PAS staining gave an intense reaction with JIM 20 antibodies during Western blot analysis. Upon deglycosylation, the reactivity with the antibody was lost due to the specificity of the JIM 20 toward the carbohydrate epitope of the isolated protein. Furthermore, a lower molecular mass polypeptide of $56 \mathrm{kDa}$ and three other polypeptides falling at a low molecular mass between 45 and $33 \mathrm{kDa}$ also showed a similar pattern of cross-reactivity (lanes 5 and 6, Fig. 1). These HRGPs could not be detected when probed with the antibodies LM1 and JIM12 during Western blot analysis (results not shown).

\section{Cross-linking analysis of PM-HRGP}

Cross-linking analysis revealed that three polypeptides with molecular size between 45 and $33 \mathrm{kDa}$ were reduced in the protein extracts from $\mathrm{H}_{2} \mathrm{O}_{2}$-treated cell suspensions, probably due to the insolubilization process of PM-HRGP (Lane 8, Fig. 1). When sodium azide, a well-known inhibitor of peroxidase, was added to the growth medium prior to the addition of $\mathrm{H}_{2} \mathrm{O}_{2}$, the levels of the polypeptides were partially restored to the previous levels indicating that they were not insolubilized (lane 9, Fig. 1).

PCR amplification of a conserved region of the HRGP gene from pearl millet

A 378-bp DNA fragment was obtained by PCR amplification of pearl millet DNA using an HRGP gene-specific primer pair. The sequence of the fragment showed $77 \%$
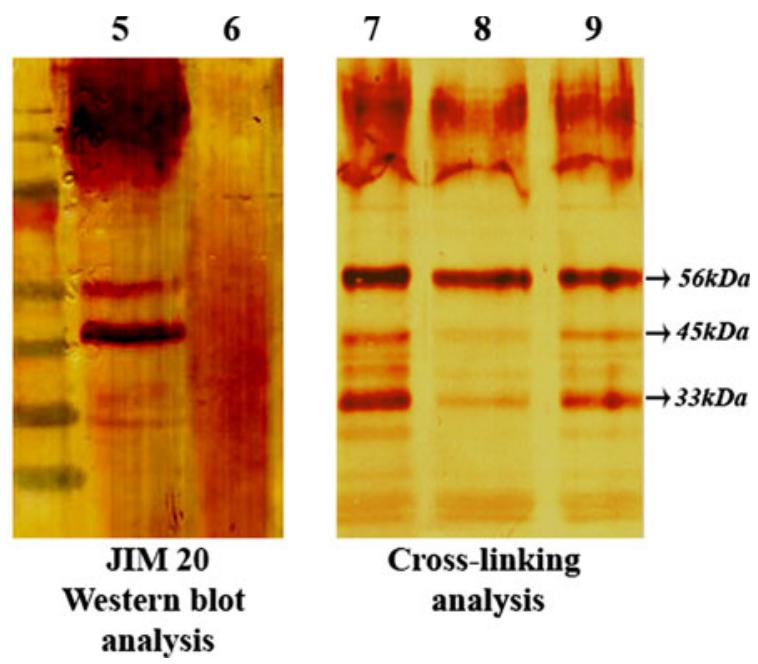

samples, respectively. For cross-linking analysis, $0.03 \% \mathrm{H}_{2} \mathrm{O}_{2}$ was added to $1 \mathrm{ml}$ of aliquots of pearl millet suspension cultured cells in the presence and absence of $0.05 \%$ sodium azide. Cells and culture medium were separated by centrifugation, subjected to SDS-PAGE, transferred to PVDF membrane and developed with JIM20. Lane 7 Untreated; $80.03 \% \mathrm{H}_{2} \mathrm{O}_{2} ; 90.03 \% \mathrm{H}_{2} \mathrm{O}_{2}$ and $0.05 \%$ sodium azide 
similarity to the Sorghum vulgare extensin gene (GenBank: X56010.1). The PCR product thus obtained was cloned and used as a homologous probe for obtaining the full-length $H R G P$ gene from pearl millet.

Genomic library preparation and screening for a full-length $H R G P$ gene in pearl millet

A fosmid genome library was prepared from physically sheared HMW DNA from pearl millet. The library was constructed using two ligation and packaging reactions to include the large-sized pearl millet genome $(2,352 \mathrm{Mb})$. Furthermore, screening of $3.6 \times 10^{5}$ clones from the library using the HRGP homologous probe identified five positive clones for the HRGP gene, each of which had the gene in a 40-kb DNA fragment of pearl millet.

\section{Restriction mapping of positive clones}

An identical hybridization reaction/pattern in the gene area for all five positive fosmids was recorded during restriction analysis. This result confirms that all five positive fosmid clones isolated from the library contain the same copy of the HRGP gene. This was also confirmed by PCR of these clones with the primers which had earlier amplified the 378-bp partial sequence of the pearl millet $H R G P$ and sequencing of the products. Furthermore, by carrying out single and double digestions with the four enzymes selected for restriction analysis, restriction sites present in an 11.8-kb region around the HRGP gene in each fosmid were mapped. The gene was thus predicted to be present in a region between two Bam HI sites situated 3.5-kb apart in the 11.8-kb region (Fig. 2). The 3.5-kb region was further sub-cloned and sequenced.

Identification of the full-length $H R G P$ gene in pearl millet

The sequence of the 3.5-kb Bam HI fragment showed the presence of a proline-rich gene sequence with a single long open reading frame of $939 \mathrm{bp}$. BLAST search of this 939-bp sequence showed close similarities of the prolinerich sequence to sorghum bicolor extensin (UniProtKB Accession Number: P24152), Zea mays extensin (P14918), Nicotiana tabacum extensin (P13983), Arabidopsis thaliana extensin protein (Q9M1G9), also with a vegetative cell wall protein of Chlamydomonas reinhardtii (Q9FPQ6), and a basic proline-rich protein of Sus scrofa (Q95JC9).

\section{Characterization of the $P M-H R G P$ gene}

In silico translational analysis revealed that the 939-bp $H R G P$ sequence encoded a protein of 312 amino acids (Fig. 3). The predicted protein of the HRGP gene from pearl millet was rich in amino acids like proline, threonine, lysine and tyrosine, showing similarity to the other

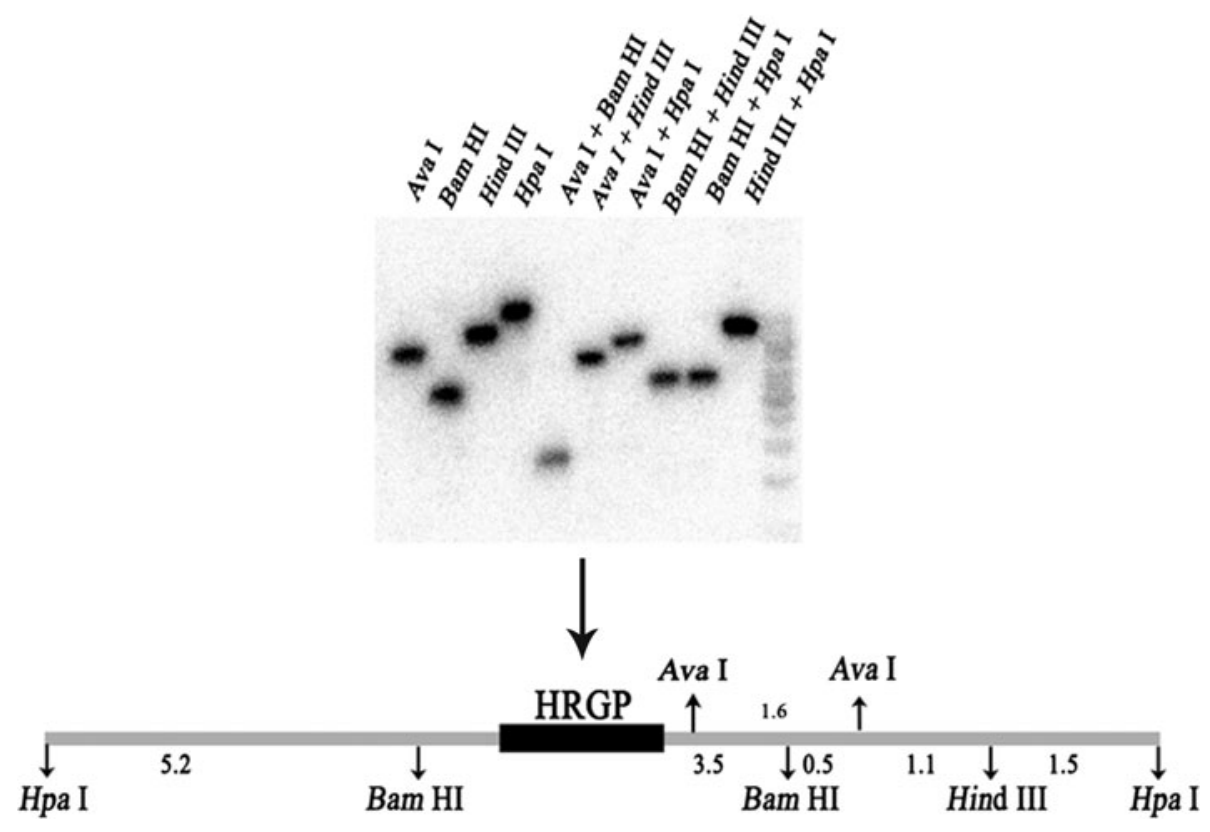

Fig. 2 Restriction analysis of the positive clones identified for the $H R G P$ gene from a genomic fosmid library of pearl millet. Restriction digestion using Bam HI, Ava I, Hind III and Hpa I on each isolated fosmid was carried out and blotted. After HRGP probe radiolabeling of the restriction blots, the $11.8 \mathrm{-kb}$ region around the $H R G P$ gene in all five positive fosmid clones were mapped. All five clones were confirmed to have the same type of $H R G P$ gene from the restriction pattern obtained. The figure represents the restriction mapping of one such positive clone from the library. The PM-HRGP gene was predicted to be situated between two Bam $\mathrm{H} 1$ sites of 3.5-kb apart on the $11.8-\mathrm{kb}$ region from the restriction pattern obtained 
-240 GACCAGTGCAGTGCACGGCGAACCCAAGGGACCAACGGGGAAGCCTCCGGCTCCTCCTCC

-180 CTCCСССACATGC CTATCCT CTCGATCGATCACGAGCGGGCATCCGAGGCCCCCACCCGG

-120 CCGCT TGCTCCGC CGTGTAT ATAAAGAGGTGGCAGGGTGAGCTCTTCTC C CAGGC CAGC

-60 CACAC ACT GATCAGAGCTTGTAGAGTGAAGT GAGTGGGGAGAGTGAGAGCGAGTGAGAGG

1 ATG GGC GCC GGC AMG GCC GCT CTG CTG CTG GCC CTG GTG GCC GTG CGC CTG GCC GTC Gag

$\begin{array}{lllllllllllllllllllllllll}M & G & \text { A } & G & \text { K } & \text { A } & \text { A } & \text { L } & \text { L } & \text { L } & \text { A } & \text { L } & \text { V } & \text { A } & \text { V } & \text { R } & \text { L } & \text { A } & \text { V } & \text { B } & 20\end{array}$

61 ATC Cag GCC GaC GCC GGC TAC GGC TAC GGC GGC GGG TAC GCG CCC ACG CCG ACC ACC CCG

$\begin{array}{llllllllllllllllllllllllll}I & Q & A & \text { D } & \text { A } & \text { G } & \text { Y } & \text { G } & \text { Y } & \text { G } & \text { G } & \text { G } & \text { Y } & \text { A } & \text { P } & \text { T } & \text { P } & \text { T } & \text { T } & \text { P } & 40\end{array}$

121 ACG CCC ACT CCG GAG AAG CCA CCC AAG GGC GGC AAG CCG CCC AAG GAG CAC GGT CCC AAG

$\begin{array}{lllllllllllllllllllllll}\text { T } & \text { P } & \text { T } & \text { P } & \text { B } & \text { K } & \text { P } & \text { P } & \text { K } & \text { G } & \text { G } & \text { K } & \text { P } & \text { P } & \text { K } & \text { B } & \text { H } & \text { G } & \text { P } & \text { K } & 60\end{array}$

181 CCT GAG AAG CCA CCC AAG GGC GAC AAG CCG CCC AAG GAG CAC GGG CAC AAG CCG GAG A.AG

$\begin{array}{lllllllllllllllllllll}\text { P } & \text { B } & \text { K } & \text { P } & \text { P } & \text { K } & \text { G } & \text { D } & \text { K } & \text { P } & \text { p } & \text { K } & \text { B } & \text { H } & \text { G } & \text { H } & \text { K } & \text { P } & \text { B } & \text { K } & 80\end{array}$

241 CCG CCC AAG GGG AAC AAG CCT CCC ACC TAC ACG CCG TCC CCG AAG CCG CCG ACG CCG CCG

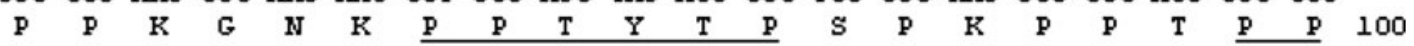

300 ACG TAC ACT CCC ACA CCG AAG CCC ACT CCG CCG GCG CCG AAG CCG AAG CCG ACG CCG CCC

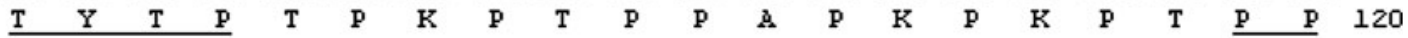

361 ACG TAC ACT CCC TCC CCG AAG CCG ACT CCG CCG ACG CCC AAG CCG ACT CCT CCG ACG CCA

$\begin{array}{lllllllllllllllllllll}\mathrm{T} & \mathrm{Y} & \mathrm{T} & \mathrm{P} & \mathrm{S} & \mathrm{P} & \mathrm{K} & \mathrm{P} & \mathrm{T} & \mathrm{p} & \mathrm{p} & \mathrm{T} & \mathrm{P} & \mathrm{K} & \mathrm{P} & \mathrm{T} & \mathrm{P} & \mathrm{P} & \mathrm{T} & \mathrm{p} & 140\end{array}$

421 AAG CCC ACC CCG CCG ACG TAC ACT CCG TCG CCG AAG CCT ACC CCG CCG ACA TAC ACT CCC

$\begin{array}{lllllllllllllllllllll}\mathrm{K} & \mathrm{P} & \mathrm{T} & \mathrm{P} & \mathrm{p} & \mathrm{T} & \mathrm{Y} & \mathrm{T} & \mathrm{P} & \mathrm{S} & \mathrm{p} & \mathrm{K} & \mathrm{p} & \mathrm{T} & \mathrm{p} & \mathrm{P} & \mathrm{T} & \mathrm{Y} & \mathrm{T} & \mathrm{p} & 160\end{array}$

481 ACG CCA AAA CCC ACT CCG CCG ACG GAC ACC CCG GCT CCC AAG CCA CCG GCG ACC AAG CCG

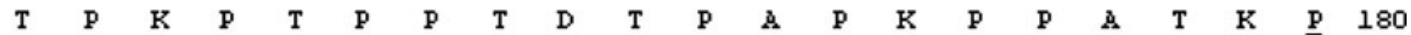

541 CCG ACC TAC ACC CCA ACT CCC AAG CCC ACC CCG CCA TCC TAC ACC CCG TCG CCT AAG CCG

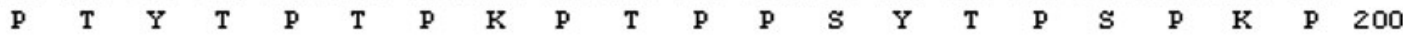

601 AAG CCA CCA ACC AAG CCG CCA ACC TAC ACC CCC ACG CCC AAG CCA ACC CCG CCA ACC TAC

$\begin{array}{lllllllllllllllllllll}\mathrm{K} & \mathrm{p} & \mathrm{p} & \mathrm{T} & \mathrm{K} & \mathrm{p} & \mathrm{p} & \mathrm{T} & \mathrm{Y} & \mathrm{T} & \mathrm{p} & \mathrm{T} & \mathrm{p} & \mathrm{K} & \mathrm{p} & \mathrm{T} & \mathrm{p} & \mathrm{p} & \mathrm{T} & \mathrm{Y} & 220\end{array}$

661 CCG CCG ACG CCC A.AG CCC ACT CCA CCG GCG CCG AAG CCG AAG CCC ACT CCC CCG ACC TAC

$\begin{array}{lllllllllllllllllllll}\mathrm{p} & \mathrm{p} & \mathrm{T} & \mathrm{p} & \mathrm{K} & \mathrm{p} & \mathrm{T} & \mathrm{p} & \mathrm{p} & \mathrm{A} & \mathrm{p} & \mathrm{K} & \mathrm{p} & \mathrm{K} & \mathrm{p} & \mathrm{T} & \mathrm{p} & \mathrm{p} & \mathrm{T} & \mathrm{Y} & 240\end{array}$

721 ACC CCT TCG CCG ACG AAG CCG A.AG CCC ACT CCT CCC CCC ACT CCC A.AG CCA ACT CCT CCG

$\begin{array}{lllllllllllllllllllll}\mathrm{T} & \mathrm{p} & \mathrm{S} & \mathrm{P} & \mathrm{T} & \mathrm{K} & \mathrm{P} & \mathrm{K} & \mathrm{p} & \mathrm{T} & \mathrm{p} & \mathrm{p} & \mathrm{p} & \mathrm{T} & \mathrm{p} & \mathrm{K} & \mathrm{P} & \mathrm{T} & \mathrm{p} & \mathrm{p} & 260\end{array}$

781 ACC TAC ACG CCG AAC CCC AAG CCA ACT CCC ACT ACT CCC AAC CCC GAA CCC ACG CCG CCG

$\begin{array}{lllllllllllllllllllll}\mathrm{T} & \mathrm{Y} & \mathrm{T} & \mathrm{p} & \mathrm{N} & \mathrm{p} & \mathrm{K} & \mathrm{p} & \mathrm{T} & \mathrm{P} & \mathrm{T} & \mathrm{T} & \mathrm{p} & \mathrm{N} & \mathrm{P} & \mathrm{B} & \mathrm{P} & \mathrm{T} & \mathrm{P} & \mathrm{p} & 280\end{array}$

841 ACC TAC AAG CCT GCT CCC AAG CCC ACA CCG CCG TCG TAC AAC AAG CCG CCG GCG GCC TCC

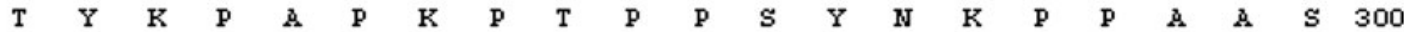

901 TAC ACC CCC AGC CCA CCG CCG CCG CAC TAC TAC AAC TGA GATCCGCCGTCTCAAGCTCGGAGCATAG

\begin{tabular}{lll|lllll|lllllll} 
Y & T & p & S & p & p & p & p & H & Y & Y & N & - & 312
\end{tabular}

962 GGTACGTACACAGCACGTGCAAAC ATTTTTCTAAC CTC TCTGTC AGACGCTAT

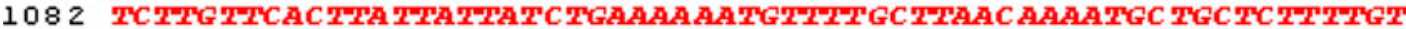

1142 TFGTTTGTGTTGCAGAAGGT GATGGAAGAGACAGT ATATGT GT GCTAGCCAGCCGGCCA

1202 AGATGAGCTGATGAAGAGAGGCCCTCGAGATCCTCCTCGTGT GTTTTCT GCCGTCCATCT

Fig. 3 The nucleotide sequence and derived amino acid sequence of the $P M-H R G P$ gene. Nucleotides are numbered from the A of the start codon $(+1)$ on the left and amino acids on the right. A putative TATA box is shown in red and underlined. The intron found in the $3^{\prime}$ untranslated region is in italics. The putative site of processing of the mature protein between Ala 23 and Asp 24 is indicated by a vertical arrow. The C-terminal single Ser (Hyp) $)_{4}$ motif is highlighted with a box. Repeating tyrosine containing peptide motifs that may play a role in the cross-linking process are underlined (color figure online) monocotyledon extensins found in sorghum, maize and rice. A single SPPPP sequence characteristic of most HRGPs of monocots except in rice (Caelles et al. 1992) was present in the motif at the $\mathrm{C}$-terminal region of the protein (Fig. 3). The new gene identified in pearl millet was named as $P M-H R G P$.

Cloning and sequencing of the $P M-H R G P$ gene region from genomic DNA and cDNA of pearl millet revealed the 
presence of an intron in the $3^{\prime}$ UTR of the $P M-H R G P$ gene with a size of $127 \mathrm{bp}$ and a splice site starting at 28-bp downstream of the stop codon (Fig. 3). An unrooted phylogenetic tree was constructed based on the comparison of $P M-H R G P$ sequences with other HRGPs from monocot and dicot species. In the phylogenetic tree, $P M-H R G P$ was positioned in a single clade with other monocot extensins and an extensin from Arabidopsis in close vicinity (Fig. 4).

Quantitative analysis of $P M-H R G P$ gene expression

Quantification of expression of the PM-HRGP gene in resistant and susceptible pearl millet samples indicated significant differences in the levels of PM-HRGP gene expression. High levels of expression of the gene were observed in resistant inoculated samples from 4 to $8 \mathrm{~h}$ after inoculation with the pathogen. A fourfold increase in the $P M-H R G P$ mRNA was observed in the $6 \mathrm{~h}$ upon inoculation with the pathogen. In case of susceptible pearl millet cultivar, no significant increase was observed both in control and inoculated seedlings at different time points (Fig. 5).

\section{Discussion}

A range of extensin class of PM-HRGP polypeptides from suspension cells of pearl millet showed affinity for the JIM 20 monoclonal antibody

The HRGPs are a superfamily of glycoproteins in higher plants. The subgroups extensins and proline-rich proteins,

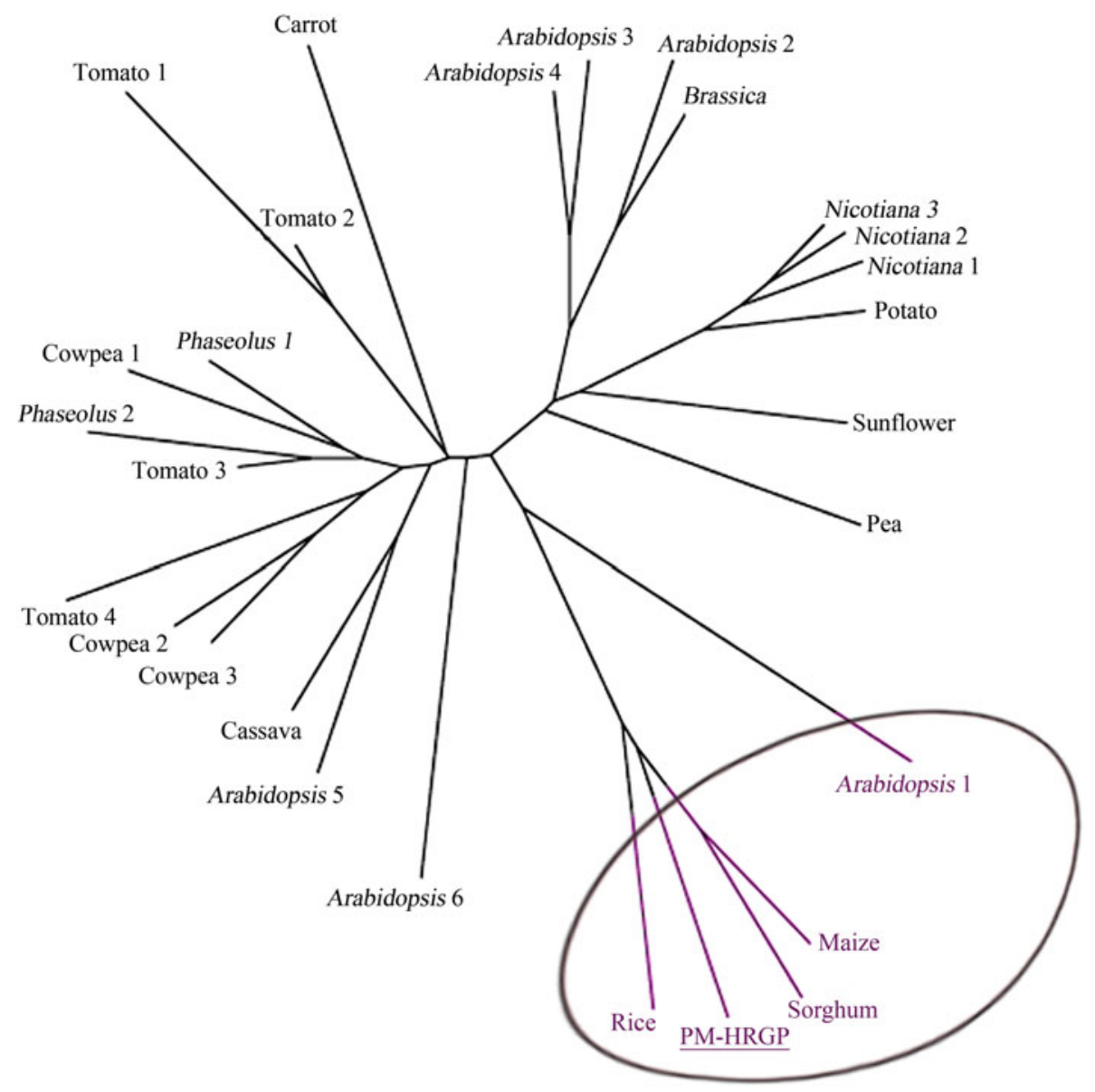

Fig. 4 Phylogenetic status of the $P M-H R G P$ gene of pearl millet among other monocot variants of extensin (HRGP) and dicot extensins. The $P M-H R G P$ was positioned in a single clade with monocot extensin genes and an extensin gene from Arabidopsis in the tree. The sequences of 27 plant extensins were obtained from the GenBank database: sorghum (X56010) maize (AJ131535) rice (X61280), cassava (AF239615) Phaseolus (M18093) (M18095) carrot (X02873) potato (Z21937) Brassica (A18812) Cowpea 1, 2 and 3 (X86029) (X86028) (X91836) Arabidopsis 1, 2, 3, 4, 5 and 6

(NM_128298, NM_101983，NM_179564，NM_129877，U43627, NM_122910) sun flower (M76546) Nicotiana 1, 2 and 3 (M34371, D13951, X71602) tomato 1,2,3 and 4 (M76671, X55681, X55685, M76670), pea (AF397029). The tree shown is an unrooted, neighborjoined tree demonstrating the relationships between various members of the HRGP extensin family from monocots and dicots. The sequences present in this tree are by no means exhaustive; rather they constitute a representative sampling of sequences available in various databases 


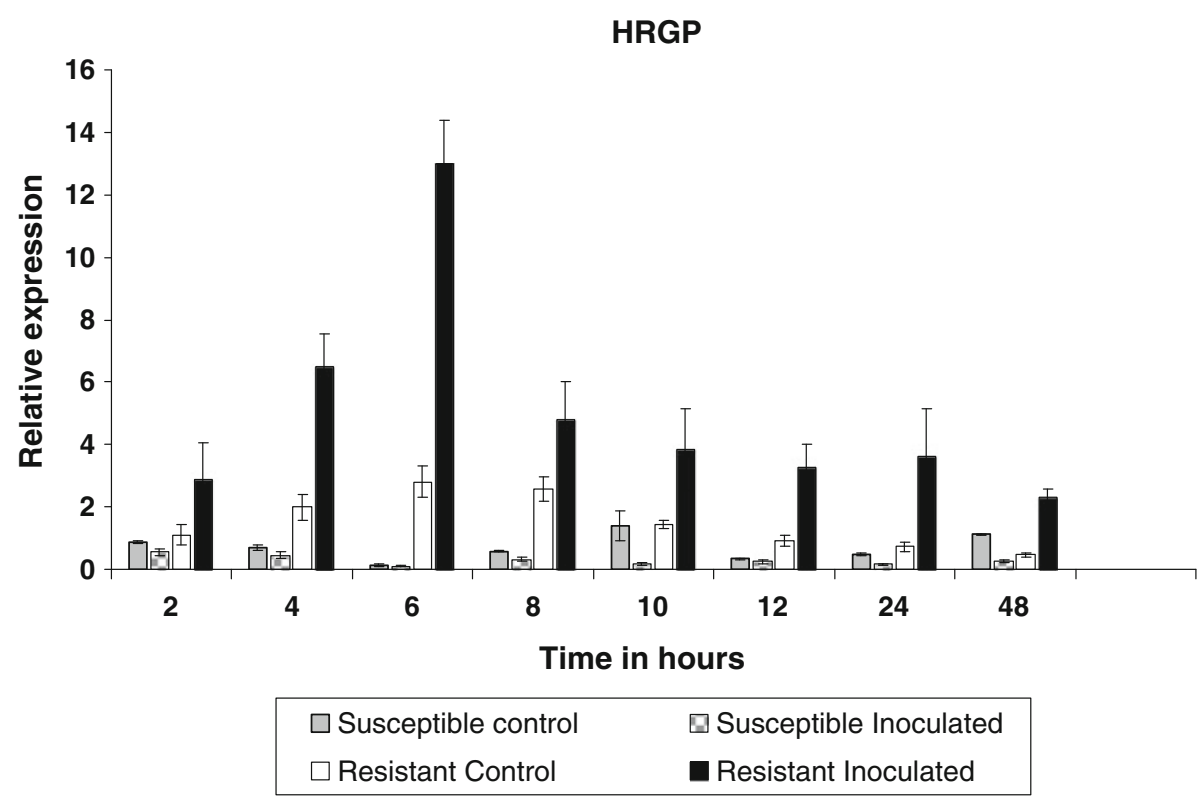

Fig. 5 Relative expression of the $P M-H R G P$ gene in susceptible and resistant cultivars of pearl millet before and after challenge inoculation using $S$. graminicola. DNA-free total RNA was isolated from 2-day-old seedlings after pathogen inoculation. Reverse transcription was carried out using oligo(dT) primer. The resulting cDNAs were amplified using gene-specific qRT-PCR primers and fold changes

of the HRGP superfamily may have a role to play in plant cell wall defense (Kieliszewski and Lamport 1994; JoseEstanyol and Puigdomenech 2000; Seifert and Roberts 2007; Showalter et al. 2010). Our previous research work suggested the involvement of functional HRGPs in successful defense against the phytopathogenic oomycete S. graminicola (Shailasree et al. 2004; Sujeeth et al. 2010). We reported a salt-inextractable, proline-rich class of HRGP reacting with the MAC265 monoclonal antibody from pearl millet seedlings (Shailasree et al. 2004; Deepak et al. 2007). MAC 265 was originally isolated by Vandenbosch et al. (1989) based on its recognition of legumespecific glycoproteins during pea-rhizobium symbiosis. In the current study, we report the presence of a Tris-SDS extractable extensin class of HRGP protein from suspension cells of pearl millet.

To investigate the presence of an extensin type of HRGP in pearl millet, we selected a panel of extensin-specific monoclonal antibodies. Western blot analysis on the TrisSDS extracted total protein from pearl millet suspension cells showed an intense reaction with the JIM 20 monoclonal antibody. JIM 20 is a monoclonal antibody, which recognizes the glycan epitope found in pea extensins (Smallwood et al. 1994; Knox et al. 1995). The monoclonal antibody JIM 12 (specific for the glycan/protein epitope) of carrot extensins (Smallwood et al. 1994) did not give any cross-reactivity with any of the polypeptides extracted from pearl millet. Interestingly, the LM1 monoclonal measured using real-time PCR. Bars represent the expression level of $P M-H R G P$ relative to zero-time controls. The values shown are means of three repeats $\pm \mathrm{SE}$ (indicated by error bars). GAPDH was chosen as an endogenous control during the experiments. Experiments were repeated twice and showed similar results

antibody, specific for the glycan epitope of extensin type of HRGP from rice (Smallwood et al. 1995), was also negative toward pearl millet extensins. The cross-reactivity of pearl millet extensin polypeptides (PM-HRGP) with JIM 20 in the current study and pearl millet PRPs with MAC 265 (Shailasree et al. 2004) suggests that the glycosylation pattern of the HRGP superfamily in pearl millet is closer to the HRGP superfamily of glycoproteins found in pea. A high molecular mass band, probably an extensin protein aggregate or polymer, and a range of lower molecular mass extensin polypeptides were identified using JIM 20. Furthermore, these extensin type of HRGP identified, upon deglycosylation with HF-pyridine, did not give any crossreaction with JIM 20, thus confirming the specificity of the antibody toward glycan epitopes in PM-HRGP.

Low molecular mass PM-HRGP polypeptides insolubilized rapidly upon treatment of pearl millet cell suspensions with hydrogen peroxide

Our previous studies showed intense accumulation of $\mathrm{H}_{2} \mathrm{O}_{2}$ within cells close to the parasite haustoria undergoing a hypersensitive-like reaction in resistant pearl millet seedlings. Furthermore, basic isoforms of a peroxidase enzyme were found more in pearl millet upon pathogen attack and elicitor treatments (Sujeeth et al. 2010). In the current study, immunoblot cross-linking analysis using JIM 20 revealed the insolubilization of three low molecular mass 
PM-HRGP polypeptides, ranging between 45 and $33 \mathrm{kDa}$ upon 10-min treatment of suspension cells with $\mathrm{H}_{2} \mathrm{O}_{2}$. Sodium azide is a well-known peroxidase inhibitor. The sodium azide sensitivity for PM-HRGP insolubilization in our analysis suggests that this process is mediated by peroxidases in the cell suspensions of pearl millet. This rapid cross-linking process is hypothesized to slow the spread of the pathogen in plants prior to the activation of transcription-dependent defenses (Lamb and Dixon 1997).

Construction of a fosmid library in pearl millet and isolation of a full-length PM-HRGP gene

To investigate the functions of extensin type of HRGP and its responses to the downy mildew pathogen $S$. gramincola, our aim was to isolate the full-length extensin gene in pearl millet. For this, a fosmid genomic library of pearl millet of fourfold haploid equivalents was constructed and screened for the presence of the extensin gene. Screening of the complete genomic library resulted in the isolation of only a single type of HRGP gene. The presence of a single gene coding for an extensin type of HRGP has been reported in other monocots like maize (Stiefel et al. 1988), sorghum (Raz et al. 1991) and rice (Caelles et al. 1992). The newly characterized HRGP gene from pearl millet was termed as PM-HRGP.

The PM-HRGP gene in pearl millet has all the characteristic features of a monocotyledon extensin type of $H R G P$

A potential TATA box was present at position -104 bp from the start site in the upstream region of the PM-HRGP gene. The 500-bp region upstream to the transcription start site of $P M-H R G P$ showed $60 \%$ homology with the upstream element of the maize extensin gene. The upstream regulatory sequences of the $H R G P$ genes responsible for tissue specificity, wound inducibility and activation during infection have been extensively studied in different species such as maize, carrot, tobacco and oilseed rape (Jose and Puigdomenech 1993). Further studies directed toward the identification of the regulatory elements present in the PM-HRGP gene could lead to a better understanding of its role during stress, pathogen attack and elicitor treatment.

Sequence comparison from the $3^{\prime}$ UTR of the $P M$ $H R G P$ gene amplified from cDNA and genomic DNA of pearl millet showed the presence of a 127-nucleotide length intron downstream of the stop codon. A similar type of intron flanked by AGgt/agGT intron consensus sequences has been reported in maize and sorghum (Stiefel et al. 1990; Raz et al. 1991). In maize, this intron in the $3^{\prime}$ UTR is reported to affect gene expression in a tissue- and promoter-dependent manner (Menossi et al. 2003). Our cDNA cloning study showed that the intron flanking sequences in $P M-H R G P$ are not similar to those found in maize and sorghum.

The predicted protein from the PM-HRGP gene showed a similarity of $54-67 \%$ with other monocot extensins. The presence of nine repeats of the hexapeptide PPTYTP and eight repeats of the pentapeptide TPKPT were observed, which were similar to those found in maize extensin (Stiefel et al. 1988). However, only a single SPKPP sequence was observed in PM-HRGP as compared to the maize extensin type of HRGP, which had 12 repeats of this sequence. Variants of all the above three kind of repeats were also observed in the PM-HRGP sequence. Several of these motifs are usually known to be present in other monocot extensins (Sommer-Knudsen et al. 1998). Prolinerich repetitive peptide motifs and their variants, singly or in combination present in the extensin gene, may constitute functional sites involved in various aspects of cell wall assembly (Kieliszewski and Lamport 1994). The posttranslational modifications like hydroxylation of prolines, glycosylation and cross-linking establish the structural and functional role of this protein in the plant cell wall. It is now assumed that repetitive HRGP polypeptides themselves are the primary determinants for the hydroxylation and glycosylation (Jamet et al. 2008).

The predicted protein from the PM-HRGP gene starts with a putative signal peptide of 24 amino acids with a cleavage site between Ala and Asp, based on the rules of von Heijne (1986), indicating an extracellular localization of the gene product. This putative cleavage site has also been observed in maize and sorghum extensins (Stiefel et al. 1988; Raz et al. 1991). It has been reported that the N-terminal signal sequence of HRGPs helps in targeting the polypeptide to the ER/Golgi for post-translational processing (Kieliszewski 2001). The C-terminal domain with a single Ser- $\left(\mathrm{Hyp}_{4}\right)$ motif characteristic of all members of the monocot extensin group was also found in the PM-HRGP confirming the presence of a Gramineae HRGP subfamily belonging to the plant cell wall HRGP family. A phylogenetic tree constructed revealed that the PM-HRGP formed a separate clade along with other monocot extensin type of HRGP genes.

Tyrosines containing YXY repeats were observed in most of the extensin protein sequences. Such sequences are involved in cross-linking (Fry 1986; Held et al. 2004). It had been shown in vitro that coupling of extensin tyrosine residues, to form mainly isodityrosine (IDT) and pulcherosine, is a peroxidase-mediated process involving $\mathrm{H}_{2} \mathrm{O}_{2}$ (Brady et al. 1996,1998; Cannon et al. 2008). This may help in the formation of an extensin network and strengthen the cell wall in arresting pathogen ingress (Cassab 1998; SommerKnudsen et al. 1998; Jose-Estanyol and Puigdomenech 2000). Increased accumulation of IDT in the cell wall 
hydrolysate has also been reported in pearl millet seedlings infected with S. graminicola (Deepak et al. 2007). The predicted protein sequence of the PM-HRGP gene characterized in the present study has only a single YGY motif near the $\mathrm{N}$-terminus that is commonly involved in extensin cross-linking. On the other hand, several repeating tyrosine residues mainly in the motif PPTYTP and also its variants such as PPTYKP and PPSYTP are also found. It remains to be elucidated if these repeating motifs have a role in the formation of stable tyrosine cross-links between different polypeptides in the pearl millet cell walls.

A differential expression study provides insight into up-regulation of $P M-H R G P$ transcripts, observed only in resistant cultivars of pearl millet during downy mildew infection

Accumulation of HRGP takes place in maize during wounding (Ludevid et al. 1990), arbuscular mycorrhizal symbiosis (Balestrini et al. 1997) and in response to fungal elicitors and infection (Showalter et al. 1985). This phenomenon was not observed during wounding in other monocots such as barley, oat, wheat or rice (Mazau and Esquerretugaye 1986; Li and McClure 1990; SommerKnudsen et al. 1998). The quantitative real-time PCR indicated an increased expression level of the PM-HRGP gene in the resistant cultivar from 4 to $8 \mathrm{~h}$ after inoculation with the pathogen, showing a fourfold increase at the 6 th hour. The expression remained at basal level in the susceptible cultivar of pearl millet upon pathogen infection. The present study confirmed the putative role of the $P M$ $H R G P$ gene in the defense reaction of pearl millet against downy mildew. Accumulation of the PM-HRGP transcripts was observed only in the resistant cultivar after inoculation with the pathogen.

\section{Concluding remarks}

The failure of pathogenic fungi to breach the plant cell wall constitutes a major component in plant defense. Our findings suggest that accumulation of an extensin class of HRGP in resistant cultivars of pearl millet in response to $S$. graminicola soon after inoculation and their possible cross-linking property in the presence of $\mathrm{H}_{2} \mathrm{O}_{2}$ may offer effective restriction for the downy mildew pathogen. Furthermore, we characterized a full-length gene coding for an extensin type of HRGP, PM-HRGP in pearl millet. The understanding of the mechanism of regulation of this gene will have importance in downy mildew disease management, especially to screen and identify resistant genotypes. In addition, biotechnological applications could improve pearl millet by providing increased resistance against downy mildew.
Compared to other important cereals such as rice, maize or sorghum, limited molecular studies have been carried out and only a few genes have been characterized in pearl millet with its huge genome size of $2,352 \mathrm{Mb}$. The complex array of defense-related genes playing a major role is yet to be characterized in this plant system. A pearl millet fosmid library covering four haploid genome equivalents in the inbred $7042 \mathrm{~S}$ cultivar has been constructed in our study and is available on request. This library will be a valuable tool for several molecular marker-based studies in pearl millet and also to identify gene candidates involved in the plant defense mechanism.

Acknowledgments We thank Marcel J.G. Sturre for technical assistance for use of the 7500 Fast Real-Time PCR system. NS acknowledges the $\mathrm{PhD}$ sandwich program of the University of Groningen (RUG) and the Faculty of Mathematics and Natural Sciences, University of Groningen for funding and support.

Open Access This article is distributed under the terms of the Creative Commons Attribution Noncommercial License which permits any noncommercial use, distribution, and reproduction in any medium, provided the original author(s) and source are credited.

\section{References}

Balestrini R, JoseEstanyol M, Puigdomenech P, Bonfante P (1997) Hydroxyproline-rich glycoprotein mRNA accumulation in maize root cells colonized by an arbuscular mycorrhizal fungus as revealed by in situ hybridization. Protoplasma 198:36-42

Bennett MD, Bhandol P, Leitch IJ (2000) Nuclear DNA amounts in angiosperms and their modern uses-807 new estimates. Ann Bot 86:859-909

Bowles DJ (1990) Defense related proteins in higher plants. Annu Rev Biochem 59:873-907

Brady JD, Sadler IH, Fry SC (1996) Di-isodityrosine, a novel tetrameric derivative of tyrosine in plant cell wall proteins: a new potential cross-link. Biochem J 315:323-327

Brady JD, Sadler IH, Fry SC (1998) Pulcherosine, an oxidatively coupled trimer of tyrosine in plant cell walls: its role in crosslink formation. Phytochem 47:349-353

Brisson LF, Tenhaken R, Lamb C (1994) Function of oxidative cross linking of cell-wall structural proteins in plant disease resistance. Plant Cell 6:1703-1712

Caelles C, Delseny M, Puigdomenech P (1992) The hydroxyprolinerich glycoprotein gene from Oryza sativa. Plant Mol Biol 18:617-619

Cannon MC, Terneus K, Hall Q, Tan L, Wang YM, Wegenhart BL, Chen LW, Lamport DTA, Chen YN, Kieliszewski MJ (2008) Self-assembly of the plant cell wall requires an extensin scaffold. Proc Natl Acad Sci USA 105:2226-2231

Cassab GI (1998) Plant cell wall proteins. Annu Rev Plant Physiol Plant Mol Biol 49:281-309

Chen J, Varner JE (1985) Isolation and characterization of cDNA clones for carrot extensin and a proline rich $33-\mathrm{kDa}$ protein. Proc Natl Acad Sci USA 82:4399-4403

Deepak S, Shailasree S, Kini RK, Hause B, Shetty SH, Mithofer A (2007) Role of hydroxyproline-rich glycoproteins in resistance of pearl millet against downy mildew pathogen Sclerospora graminicola. Planta 226:323-333 
El-Gendy W, Brownleader MD, Ismail H, Clarke PJ, Gilbert J, El-Bordiny F, Trevan M, Hopkins J, Naldrett M, Jackson P (2001) Rapid deposition of wheat cell wall structural proteins in response to Fusarium-derived elicitors. J Exp Bot 52:85-90

Evans IM, Gatehouse LN, Gatehouse JA, Yarwood JN, Boulter D, Croy RRD (1990) The extensin gene family in oilseed rape (Brassica napus L.) — characterization of sequences of representative members of the family. Mol Gen Genet 223:273-287

Fry SC (1986) Cross-linking of matrix polymers in the growing cell walls of angiosperms. Annu Rev Plant Physiol 37:165-186

Fulton TM, Chunwongse J, Tanksley SD (1995) Microprep protocol for extraction of DNA from tomato and other herbaceous plants. Plant Mol Biol Rep 13:207-209

Held MA, Tan L, Kamyab A, Hare M, Shpak E, Kieliszewski MJ (2004) Di-isodityrosine is the intermolecular cross-link of isodityrosine-rich extensin analogs cross-linked in vitro. J Biol Chem 279:55474-55482

Jackson PAP, Galinha CIR, Pereira CS, Fortunato A, Soares NC, Amancio SBQ, Ricardo CPP (2001) Rapid deposition of extensin during the elicitation of grapevine callus cultures is specifically catalyzed by a 40-kilodalton peroxidase. Plant Physiol 127:1065-1076

Jamet E, Albenne C, Boudart G, Irshad M, Canut H, Pont-Lezica R (2008) Recent advances in plant cell wall proteomics. Proteomics 8:893-908

Jose M, Puigdomenech P (1993) Structure and expression of genes coding for structural proteins of the plant cell wall. New Phytol 125:259-282

Jose-Estanyol M, Puigdomenech P (2000) Plant cell wall glycoproteins and their genes. Plant Physiol Biochem 38:97-108

Kieliszewski MJ (2001) The latest hype on Hyp-O-glycosylation codes. Phytochem 57:319-323

Kieliszewski MJ, Lamport DTA (1994) Extensin-repetitive motifs, functional sites, posttranslational codes, and phylogeny. Plant $\mathbf{J}$ 5:157-172

Knox JP, Peart J, Neill SJ (1995) Identification of novel cell, surface epitopes using a leaf epidermal strip assay system. Planta 196:266-270

Lamb C, Dixon RA (1997) The oxidative burst in plant disease resistance. Annu Rev Plant Physiol Plant Mol Biol 48:251-275

Léder I (2004) Sorghum and millets. In: Encyclopedia of life support systems. Eolss Publishers, Oxford

Li ZC, McClure JW (1990) Soluble and bound hydroxyproline-rich glycoproteins in control and wounded oat and barley primary leaves. Phytochem 29:2811-2813

Livak KJ, Schmittgen TD (2001) Analysis of relative gene expression data using real-time quantitative PCR and the $2^{-\Delta \Delta C T}$ method. Methods 25:402-408

Lowry OH, Rosebrough NJ, Farr AL, Randall RJ (1951) Protein measurement with the Folin phenol reagent. J Biol Chem 193:265-275

Ludevid MD, Ruizavila L, Valles MP, Stiefel V, Torrent M, Torne JM, Puigdomenech P (1990) Expression of genes for cell wall proteins in dividing and wounded tissues of Zea mays L. Planta 180:524-529

Mazau D, Esquerretugaye MT (1986) Hydroxyproline-rich glycoprotein accumulation in the cell walls of plants infected by various pathogens. Physiol Mol Plant Pathol 29:147-157

Menossi M, Rabaneda F, Puigdomenech P, Martinez-Izquierdo JA (2003) Analysis of regulatory elements of the promoter and the 3' untranslated region of the maize HRGP gene coding for a cell wall protein. Plant Cell Rep 21:916-923

Merkouropoulos G, Barnett DC, Shirsat AH (1999) The Arabidopsis extensin gene is developmentally regulated, is induced by wounding, methyl jasmonate, abscisic and salicylic acid, and codes for a protein with unusual motifs. Planta 208:212-219
Raz R, Cretin C, Puigdomenech P, MartinezIzquierdo JA (1991) The sequence of a hydroxyproline-rich glycoprotein gene from Sorghum vulgare. Plant Mol Biol 16:365-367

Sambrook J, Fritsch EF, Maniatis T (1989) Molecular cloning: a laboratory manual, 2nd edn. Cold Spring Harbor Laboratory Press, New York

Seifert GJ, Roberts K (2007) The biology of arabinogalactan proteins. Annu Rev Plant Biol 58:137-161

Shailasree S, Kini KR, Deepak S, Kumudini BS, Shetty HS (2004) Accumulation of hydroxyproline-rich glycoproteins in pearl millet seedlings in response to Sclerospora graminicola infection. Plant Sci 167:1227-1234

Showalter AM (1993) Structure and function of plant cell wall proteins. Plant Cell 5:9-23

Showalter AM, Bell JN, Cramer CL, Bailey JA, Varner JE, Lamb CJ (1985) Accumulation of hydroxyproline-rich glycoprotein messenger-RNAs in response to fungal elicitor and infection. Proc Natl Acad Sci USA 82:6551-6555

Showalter AM, Keppler B, Lichtenberg J, Gu DZ, Welch LR (2010) A bioinformatics approach to the identification, classification, and analysis of hydroxyproline-rich glycoproteins. Plant Physiol 153:485-513

Singh SD, Gopinath R (1985) A seedling inoculation technique for detecting downy mildew resistance in pearl millet. Plant Dis 69:582-584

Smallwood M, Beven A, Donovan N, Neill SJ, Peart J, Roberts K, Knox JP (1994) Localization of cell wall proteins in relation to the developmental anatomy of the carrot root apex. Plant J 5:237-246

Smallwood M, Martin H, Knox JP (1995) An epitope of rice- and threonine-rich and hydroxyproline-rich glycoprotein is common to cell wall and hydrophobic plasma membrane glycoproteins. Planta 196:510-522

Sommer-Knudsen J, Bacic A, Clarke AE (1998) Hydroxyproline-rich plant glycoproteins. Phytochem 47:483-497

Stiefel V, Perezgrau L, Albericio F, Giralt E, Ruizavila L, Ludevid MD, Puigdomenech P (1988) Molecular cloning of cDNAs encoding a putative cell-wall protein from Zea mays and immunological identification of related polypeptides. Plant Mol Biol 11:483-493

Stiefel V, Ruizavila L, Raz R, Valles MP, Gomez J, Pages M, Martinez Izquierdo JA, Ludevid MD, Langdale JA, Nelson T, Puigdomenech P (1990) Expression of a maize cell wall hydroxyproline-rich glycoprotein gene in early leaf and root vascular differentiation. Plant Cell 2:785-793

Sujeeth N, Deepak S, Shailasree S, Kini RK, Shetty SH, Hille J (2010) Hydroxyproline-rich glycoproteins accumulate in pearl millet after seed treatment with elicitors of defense responses against Sclerospora graminicola. Physiol Mol Plant Pathol 74:230-237

Templeton MD, Dixon RA, Lamb CJ, Lawton MA (1990) Hydroxyproline-rich glycoprotein transcripts exhibit different spatial patterns of accumulation in compatible and incompatible interactions between Phaseolus vulgaris and Colletotrichum lindemuthianum. Plant Physiol 94:1265-1269

Thakur RP, Rai KN, Rao VP, Rao AS (2001) Genetic resistance of pearl millet male-sterile lines to diverse Indian pathotypes of Sclerospora graminicola. Plant Dis 85:621-626

Vandenbosch KA, Bradley DJ, Knox JP, Perotto S, Butcher GW, Brewin NJ (1989) Common components of the infection thread matrix and the intercellular space identified by immunocytochemical analysis of pea nodules and uninfected roots. EMBO J 8:335-341

Vanholst GJ, Varner JE (1984) Reinforced polyproline-II conformation in a hydroxyproline-rich cell wall glycoprotein from carrot root. Plant Physiol 74:247-251 
Vasil V, Vasil IK (1981) Somatic embryogenesis and plant regeneration from suspension cultures of pearl millet (Pennisetum americanum). Ann Bot 47:669-678

von Heijne $G$ (1986) A new method for predicting signal sequence cleavage sites. Nucleic Acids Res 14:4683-4690

Yoshiba Y, Aoki C, Iuchi S, Nanjo T, Seki M, Sekiguchi F, Yamaguchi-Shinozaki K, Shinozaki K (2001) Characterization of four extensin genes in Arabidopsis thaliana by differential gene expression under stress and non-stress conditions. DNA Res 8:115-122

Zimmermann P, Hirsch-Hoffmann M, Hennig L, Gruissem W (2004) Genevestigator Arabidopsis microarray database and analysis toolbox. Plant Physiol 136:2621-2632 